\title{
Construção de uma horta vertical: Uma abordagem na Educação Infantil para sensibilizar os estudantes sobre os cuidados com o meio ambiente
}

\author{
Building a Vertical Vegetable Garden: An Early Childhood \\ Approach to Sensitizing Students on Environmental Care
}

Tainá Griep Maronn (taina.maronn@ hotmail.com)

Universidade Federal da Fronteira Sul (UFFS)

\begin{abstract}
Resumo: Cada vez mais vêm sendo discutidas questões relacionadas à reciclagem e à reutilização de materiais. Assim sendo, a consciência e a responsabilidade de cada cidadão na busca de um mundo mais sustentável e próspero nos instiga a buscar métodos e iniciativas eficazes e simples para a preservação do planeta. Um desses métodos pode ser a conversão de pequenas ações em resoluções mais saudáveis e criativas. Dentre os quais pode ser utilizado, como exemplo, a construção de uma horta vertical. A construção da horta vertical teve como objetivos: propiciar momentos de reflexão acerca da responsabilidade ambiental; fazer a montagem da horta, usando plantas pequenas; compreender as contribuições de uma horta vertical no contexto da escola; e conscientizar a importância da reutilização de objetos recicláveis descartados no cotidiano. Esse trabalho buscou desenvolver uma horta vertical, reaproveitando garrafas PET na creche localizada no município de São Pedro do Butiá. A partir disso, o projeto realizado foi um meio encontrado de sensibilizar de que, com pouco trabalho e muita criatividade, é possível desenvolver atividades sustentáveis com custo mínimo.
\end{abstract}

Palavras-chave: Reciclagem; Garrafa PET; Horta Vertical.

Abstract: Issues related to recycling and material reuse are increasingly being discussed. Therefore, the conscience and responsibility of each citizen in search of a more sustainable and prosperous world urges us to seek effective and simple methods and initiatives for the preservation of the planet. One such method may be to convert small actions into healthier, more creative resolutions. Among which can be used as an example the construction of a vertical garden. The construction of the vertical garden had the following objectives: to provide moments of reflection on environmental responsibility; assemble the garden using small plants; understand the contributions of a vertical garden in the school context; and raise awareness of the importance of reusing recyclable objects discarded in daily life. This work aimed to develop a vertical garden, reusing PET bottles in the nursery located in São Pedro do Butiá. From this, the project was a way to raise awareness that with little work and a lot of creativity, it is possible to develop sustainable activities with minimal cost. 


\section{Vol. 2, n. 3 - Edição Especial: Ciclos Formativos em Ensino de Ciências}

Keywords: Recycling; Pet bottle; Vertical garden.

\section{INTRODUÇÃO}

Atualmente cada vez mais se aborda sobre a reciclagem e a reutilização de materiais utilizados no dia a dia. Existem muitas empresas que incentivam sobre a responsabilidade ambiental, as quais apresentam projetos de recolhimento de embalagens, encaminhando estas para o descarte ou para serem reutilizadas. $\mathrm{O}$ consumismo é considerado um grande obstáculo proporcionado pelas novas tecnologias de fabricação, que asseguram ao consumidor o acesso aos produtos, assim ocasionando uma preocupação com o meio ambiente do novo perfil de consumidor (MUELLER, 2013).

Uma das formas para reverter essas circunstâncias, seria a sustentabilidade ambiental, uma vez que é por meio da sustentabilidade que será possível permitir uma qualidade de vida, pensando nas necessidades do presente sem comprometer a aptidão de gerações futuras. Entretanto, dessa maneira toda sociedade tem a necessidade de educar suas ações, determinar os limites de consumo e isso não está relacionado apenas com os consumidores, como também com as empresas que devem desenvolver produtos ecologicamente certos e com materiais que não causam danos ao meio ambiente (GUAITOLINI, 2013).

Dessa maneira, a ausência da sensibilização nas atitudes humanas nos exibem a importância da educação ambiental em nossa sociedade para o desenvolvimento do pensamento crítico das pessoas (REIGOTA, 2012). Assim, sendo os indivíduos devem refletir sobre as ações que vem realizado e desenvolver maneiras de mudar os locais aos quais estão inseridos, para assim desenvolver não somente intervenções de modo individual, porém no coletivo, sendo capaz valorizar o ambiente (JACOBI, 1997).

\footnotetext{
Assim, ao considerar que a Educação Ambiental a abordagem educacional que visa uma mudança de paradigmas rumo ao do desenvolvimento sustentável, entendemos que a escola deva não só ser um agente de mudanças, mas deve se ver também como um objeto de mudanças, palco de atuação prática dos novos valores que são colocados pela Educação Ambiental (ANDRADE, 2000, p.6).
} 


\section{Vol. 2, n. 3 - Edição Especial: Ciclos Formativos em Ensino de Ciências}

A concepção da sustentabilidade implica, provoca, uma interligação de justiça social, qualidade de vida, equilíbrio ambiental e uma interrupção com o padrão contemporâneo de desenvolvimento (JACOBI, 1997). Nessa perspectiva, de acordo com Reigota (1998), a educação ambiental aborda algumas preposições pedagógicas com foco principal na conscientização, modificação do comportamento, desenvolvimento da capacidade, competências de avaliação e participação dos educandos. Entretanto, segundo Pádua e Tabanez (1998), a educação ambiental possibilita um maior conhecimento, modificações e aprimoramentos de competências, condições básicas para permitir uma maior inserção e equilíbrio dos indivíduos com o meio ambiente.

A educação ambiental está vinculada a sustentabilidade socioambiental e apresenta como propósito a modificação do meio ambiente, a partir de métodos considerados mais pertinentes de utilização do solo, levando em consideração a variedade naturais e contextuais, dos contextos culturais (SORRENTINO et al., 2005). Nesse sentido, atitudes envolvendo uma melhoria no desenvolvimento da conscientização do ambiente, levando em conta um mundo mais sustentável, o projeto de realização de hortas verticais, demonstra-se como um importante instrumento apropriado para isso. A horta vertical no meio escolar permite a utilização de várias atividades pedagógicas na educação ambiental e alimentar, contribuindo na conscientização ambiental, propiciando ligações de solidariedade e estimula o convívio no coletivo. Assim como, possibilita a produção de alimentos pelos alunos, sendo uma prática sustentável, e sendo possível ainda de ser perpassados para seus familiares, permitindo a construção de uma horta na família, permitindo hábitos saudáveis para toda a família (FETTER et al., 2006).

Conforme Serrano (2003), a horta escolar é considerada como um componente capaz de levar em consideração temática que tem relação com à Educação Ambiental e também decorrentes a sustentabilidade, sendo possível além de fazer uma relação teórica e prática, contribui para o processo de ensino e aprendizagem, sendo considerada ainda como uma forma capaz de desenvolvimento dos conteúdos interdisciplinarmente.

As pessoas apresentam diferentes pontos de vista sobre o conceito de educação ambiental, sendo possível realizar conteúdos teóricos, e relacionado a estes várias 


\section{Vol. 2, n. 3 - Edição Especial: Ciclos Formativos em Ensino de Ciências}

atividades práticas (SAUVÉ, 2005). Neste sentido se faz necessário realizar atividades práticas nesta temática, como por exemplo, a construção de uma horta vertical utilizando materiais recicláveis e de baixo custo. Assim, esse trabalho buscou desenvolver uma horta vertical (re)aproveitando essas garrafas PET na creche localizada no município de São Pedro do Butiá, cidade vizinha de nossa instituição. Buscamos com esta atividade uma maior aprendizagem sobre Educação ambiental, relacionando a concepção teórica com a prática e com isso, estabelecer diferentes maneiras de desenvolver temas transversais.

Assim sendo, esta atividade foi desenvolvido com as seguintes finalidades: propiciar momentos de reflexão acerca da responsabilidade ambiental; fazer a montagem da horta, usando plantas pequenas; compreender as contribuições de uma horta vertical no contexto da escola; e conscientizar a importância da reutilização de objetos recicláveis descartados no cotidiano.

\section{DESCRIÇÃO DAS ATIVIDADES}

Essa atividade foi realizada pelas alunas da $6^{\circ}$ do curso de Ciências Biológicas - Licenciatura da Universidade Federal da Fronteira Sul (UFFS), Campus Cerro Largo, na qual foi feita a construção de uma Horta Vertical utilizando paletes e garrafas pets, com o intuito de propiciar para os alunos uma maior concepção da relevância que uma horta vertical pode apresentar.

A construção desta horta vertical foi desenvolvida com os alunos da turma do primeiro ano da creche, localizada na cidade de São Pedro do Butiá. Para a confecção desta foram utilizados somente materiais recicláveis, visando um baixo custo, priorizando o uso de objetos recicláveis e de mudas de chás trazidas de casa. Para tanto, utilizamos dois paletes de madeira, garrafas PET com capacidade de 2 litros, cerca de 5 metros de arame, terra adubada, mudas de chás como melissa, camomila, boldo e hortelã.

No primeiro momento, caminhamos pela creche para conhecermos o local, depois disso juntamente com a diretora escolhemos o local mais apropriado para a execução desse projeto. Após direcionamos ao local levando todo o material necessário para a realização desta atividade, que havíamos trazido de casa. Em seguida, nos encaminhamos 


\section{Vol. 2, n. 3 - Edição Especial: Ciclos Formativos em Ensino de Ciências}

até a sala de aula, cumprimentamos as professoras e os alunos, depois levamos estes em fila juntamente com a professora para o local escolhido. Desde o primeiro momento as crianças estavam curiosas e interessadas em saber o que iríamos realizar. No momento em que íamos explicando como seria realizada a atividade, estavam bem atentas.

Entretanto, primeiramente distribuímos uma muda de chá para cada um dos alunos, que nos questionavam para que servia aquele chá. Também procuramos interagir com eles fazendo pergunta como, por exemplo, se “eles gostavam de chá?”. Depois que os 14 alunos receberam a muda chá, distribuímos um litro cortado ao meio para cada um, para realizar o plantio, logo após que receberam o litro, nos perguntaram porque tinha aqueles furinhos na parte inferior, alguns alunos já sabiam o motivo disso, e juntamente explicamos para eles o porquê disto. Então, começamos a dar início ao plantio dos chás, em que chamamos três alunos por vez, para perto da bolsa onde estava a terra, para assim efetuar o plantio, sempre com nosso auxílio, e também com uma explicação de como deveriam fazer o plantio, primeiramente colocando a terra e logo após a muda. Após todos os terem realizado o plantio da muda de chá que haviam recebido, fixamos os litros nos paletes com o arame, e por último cada criança molhou uma muda, e assim explicamos também a importância de melhor as plantas para eles. Na imagem abaixo (Fig. 1) é possível ver o resultado final da horta.

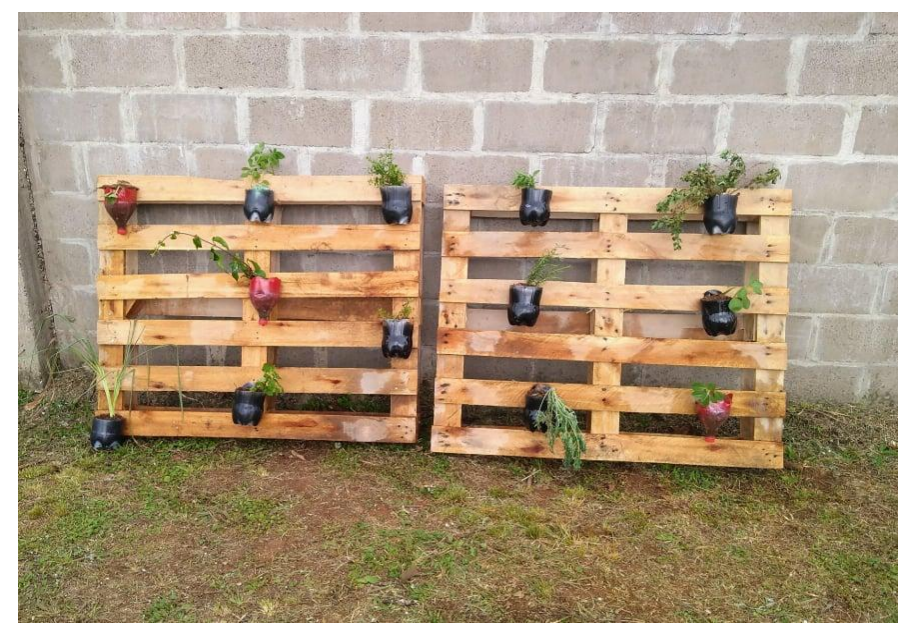

Figura 1- Imagem da horta vertical realizada com os alunos da creche. 


\section{Vol. 2, n. 3 - Edição Especial: Ciclos Formativos em Ensino de Ciências}

\section{DISCUSSÃO DA PRÁTICA}

Essa atividade prática envolvendo a educação ambiental, pode ser utilizado nas aulas práticas de várias disciplinas para garantir uma aprendizagem mais significativa dos conteúdos teóricos abordados em sala de aula, possibilitando assim um meio de interação da teoria com a prática. De acordo com Andrade e Massabni (2011), as atividades práticas possibilitam a concepção de novos conhecimentos que somente com a aula teórica não seria possível.

A partir dessa atividade é possível ocorrer uma aproximação dos professores com os alunos, tendo a possibilidade ainda de serem abordados vários conteúdos, ou seja, propiciando um estudo interdisciplinar. A utilização de aulas práticas na educação ambiental como estas, possibilitam serem trabalhadas maneiras de plantio, o cultivo e o cuidado com as hortaliças. Utilizando a construção desta horta vertical é possível ainda abordar aspectos relacionados a educação ambiental e alimentar, uma vez que a partir das junções de conceitos teóricos e práticos, constituindo o desenvolvimento de conteúdos de maneira interdisciplinar (MORGADO, 2006).

Como os alunos apresentam o papel de aprendizes e observadores, eles têm como grande relevância no sentido do questionamento da atividade realizada. Além disso deve ser feita uma discussão com todo o grupo como também com o professor sobre o que aconteceu durante a prática para assim ser possível de conceber hipóteses para a partir daí elaborarem suas respostas. Assim sendo, alguns alunos criaram uns questionamentos sobre a aula prática, como por exemplo: perguntaram porque tinha aqueles furinhos na parte de baixo do litro? Para que servia aqueles chás? entre outras. Dessa maneira é possível perceber que a realização de uma atividade prática é muito importante, pois tem como intuito de proporcionar a capacidade de formulação de hipóteses, pois foram levantados vários argumentos para responder estas perguntas. No entanto, cabe ressaltar que a presença do professor é indispensável, pois este auxilia nas explicações dos resultados obtidos. 


\section{Vol. 2, n. 3 - Edição Especial: Ciclos Formativos em Ensino de Ciências}

As aulas práticas tem a finalidade de permitir uma maior interação entre os alunos e deixá-los motivados. Assim sendo, o professor tem um papel muito importante, segundo Hodson (1994), o professor deve ajudar os alunos na exploração, desenvolvimento e modificação de suas 'concepções ingênuas' sobre determinados assuntos e relacioná-los ao conhecimento científico, sem desconsiderá-los. Sendo ainda que os alunos devem ser incentivados a desenvolver suas opiniões, permitindo e estimulando uma reflexão sobre a finalidade de suas ideias para compreender argumentos levantados durante a atividade.

Ao longo desse momento, observou-se o envolvimento e atuação direta dos alunos nas atividades sugeridas no plano de ação, construído principalmente pelos discentes com orientação dos professores, além do alto grau de responsabilidade e comprometimento dos educandos em consolidar novas posturas e hábitos dentro da comunidade escolar.

Dessa maneira, no decorrer da atividade, buscamos desenvolver maneiras que propiciam ao aluno certa sensibilização sobre o meio ambiente e a relevância que algumas atividades apresentam para a conservação deste. Procuramos demonstrar como é capaz de se produzir alimentos de forma simples e sustentável utilizando materiais de baixo custo e recicláveis. Atividades como estas demonstram que o Ensino não é concebível apenas em sala de aula, sendo possível utilizar locais variados, e apresentando a capacidade de abordar as disciplinas de forma interdisciplinar em contexto tanto ambiental como também social.

Entretanto é de praxe sugerir circunstâncias alternativas para a efetivação desta atividade prática, com a intenção de desafiar a explicação encontrada pelos alunos. Sendo assim, de um modo geral os alunos envolvem-se elaborando perguntas e respostas e demonstrando estar interessados com a investigação. Nesse sentido, de acordo com o que foi visto também por Fernandes (2012), vale salientar a relevância de uma prática dialógica interativa que permite aos alunos uma maior participação.

Cabe ressaltar que essa atividade foi fundamental para permitir uma o diálogo entre os alunos e o professor, participação ativa na atividade, além de ser um meio de reutilizar materiais recicláveis, mas possibilita aos alunos a compreensão, e assim, melhores são os 


\section{Vol. 2, n. 3 - Edição Especial: Ciclos Formativos em Ensino de Ciências}

resultados de sensibilização, respeito e valorização da natureza. Como também as crianças se tornam mais conscientes e podem levar ensinamentos ecológicos para sua vida, desenvolvendo maneiras de mudar a postura da sociedade com o meio ambiente.

Além disso, no final da atividade vários alunos mencionaram que iriam falar para os seus pais, plantar os chás em suas casas dessa maneira, como havíamos realizado nesta aula. Sendo isso imprescindível para auxiliar no desenvolvimento sustentável, havendo a possibilidade dos alunos levar essa proposta para suas casas, possibilitando uma melhoria na qualidade dos seus familiares (COSTA; SOUZA; PEREIRA, 2015).

\section{CONCLUSÃO}

A abordagem de construção de hortas verticais, pode ser, utilizada com os alunos de diversas faixas etárias, neste caso com ênfase a educação infantil sendo que é nesses períodos que podem ser desenvolvidas a construção de conceitos e atitudes que podem ser perpassadas para toda a vida escolar contribuindo para a consciência ambiental. Entretanto, a aprendizagem relacionada a esta prática pode auxiliar na melhoria dos hábitos atuais e futuros. A utilização das hortas verticais é considerada ainda um recurso de grande relevância no ensino da Educação Ambiental, sendo possível realizar uma contextualização e também uma interdisciplinaridade, envolvendo ainda concepções de sustentabilidade.

Devido os projetos sustentáveis serem imprescindíveis, estão sendo cada vez mais discutidos. A partir disso corrobora-se a atividade realizada como uma forma de sensibilizar, os alunos da escola, como também os professores e funcionários, permitindo que com pouco trabalho e muita criatividade, é provável de serem realizadas atividades visando a sustentabilidade utilizando materiais recicláveis e com custo mínimo.

Essa atividade também teve como finalidade estimular os professores a desenvolver atividades diferentes em sala de aula, a partir de atividades práticas como estas e não apenas envolver conteúdos teóricos, mas também práticos envolvendo a educação 
Vol. 2, n. 3 - Edição Especial: Ciclos Formativos em Ensino de Ciências

ambiental. Para que assim, os alunos tenham a capacidade levar consigo ações sustentáveis para fora da escola, aplicando-as em suas casas ou até mesma na rua.

\section{REFERÊNCIAS}

ANDRADE, D. F. de. Implementação da Educação Ambiental em escolas: uma reflexão. In: Fundação Universidade Federal do Rio Grande. Revista do Mestrado em Educação Ambiental, v. 4, p. 12-16, 2000.

ANDRADE, T. L. de; MAZAROTTO, E. J; SILVA, C. B. da. Horta vertical com garrafas pet: uma alternativa para educação ambiental nas escolas. Visão Acadêmica, Curitiba, v. 17, n. 3, p.29-37, 2016. Disponível em:

https://www.researchgate.net/publication/313959113_HORTA_VERTICAL_COM_GA RRAFAS_PET_UMA_ALTERNATIVA_PARA_EDUCACAO_AMBIENTAL_NAS_ ESCOLAS. Acesso em: 23 nov. 2018.

BRASIL. Secretaria de Educação Fundamental. Parâmetros Curriculares Nacionais: meio ambiente e saúde. Brasília. 1997. V.9.

COSTA, C. A. G. da; SOUZA, J. T. A. PEREIRA, D. D. Horta Escolar: alternativa para promover educação ambiental e desenvolvimento sustentável no cariri paraibano. Revista Polêm!ca, v. 15, n. 3, 2015. Disponível em: https://www.epublicacoes.uerj.br/index.php/polemica/article/view/19350/14122. Acesso em: 22 ago. 2019.

ESTEVAM, P. M. S; ARDENGHI, A. A. F; ACRANI, S. Construção de horta vertical na escola, uma ferramenta didática para o ensino de Biologia. Revista Encontro de Formação de Professores, Uberaba v. 1, n. 1, p. 1-5, 2013. Disponível em: http://revistas.uniube.br/index.php/efp/article/view/633/772. Acesso em: 13 ago. 2018

FERNANDES, M.C. et al. Atividade prática como recurso alternativo para o ensino de biologia. Anais do IV ENEBIO e II EREBIO da Regional 4, Goiânia, 2012. (CD ROM).

GUAITOLINI, B. S. Sustentabilidade Ambiental. Disponível em:

$<$ http://www.administradores.com.br/artigos/economia-e-financas/sustentabilidadeambiental/23978/>. Acesso em: 23 nov. 2018. 


\section{Vol. 2, n. 3 - Edição Especial: Ciclos Formativos em Ensino de Ciências}

HODSON, D. Hacia um enfoque más crítico del trabajo de laboratório. Enseñanza de Las Ciencias, Barcelona, v. 12, n. 3, p. 299-313, 1994.

JACOBI, P. et al. (orgs.). Educação, meio ambiente e cidadania: reflexões e experiências. São Paulo, Brasil, SMA, 1977.

LOUREIRO, C. F. B. Educação ambiental crítica: contribuições e desafios. In: Vamos cuidar do Brasil: conceitos e práticas em educação ambiental na escola. (Mello, S.S. \& Trajber, R. (org.)). Brasília: Ministério da Educação: UNESCO, 2007, p. 65-72.

MARQUES, L. L, et al. Projeto Horta Vertical: trabalhando conceitos ecológicos nas séries iniciais. Anais...São Gabriel, 2012. v. 4, n. 1. Disponível em: <http://seer.unipampa.edu.br/index.php/siepe/article/view/673 2 . Acesso em: 13 ago. 2018 .

MORGADO, F. da S. A horta escolar na educação ambiental e alimentar: experiência do Projeto Horta Viva nas escolas municipais de Florianópolis. 2006. $45 \mathrm{p}$.

MUELLER, C. F. Logística Reversa Meio-ambiente e Produtividade. 2005, Disponível em: http://www.tecspace.com.br/paginas/aula/faccamp/Rev/Artigo01.pdf. Acesso em: 10 jun. 2019.

OLIVEIRA, D. L. de H. et al. Horta Vertical: Um Instrumento de Educação Ambiental na Escola. Revista Eletrônica do Mestrado em Educação Ambiental, Minas Gerais jan/jun, 2014. Disponível em: https://periodicos.furg.br/remea/article/viewFile/3529/2921_.Acesso em: 14 ago. 2018.

PÁDUA, S.; TABANEZ, M. (orgs.). Educação ambiental: caminhos trilhados no Brasil. São Paulo: Ipê, 1998

REIGOTA, M. O que é Educação Ambiental. 2. ed. São Paulo: Brasiliense. (Coleção Primeiros Passos), 2012.

REIGOTA, M. Desafios à educação ambiental escolar. In: JACOBI, P. et al. (orgs.). Educação, meio ambiente e cidadania: reflexões e experiências. São Paulo: SMA, 1998. p.43-50. 
Revista Insignare Scientia

Vol. 2, n. 3 - Edição Especial: Ciclos Formativos em Ensino de Ciências

SAUVÉ, L. Uma cartografia das correntes em Educação Ambiental. In: SATO, M.; CARVALHO, I. C. M. (Orgs.). Educação Ambiental - pesquisas e desafios. Porto Alegre: Artmed, 2005.

SERRANO, C. M. L. Educação Ambiental e consumerismo em Unidades de Ensino Fundamental de Viçosa-MG. 2003. 91f. Tese( Doutorado em Magister Scientiae) Programa de Pós Graduação em Ciências Florestal, Universidade Federal de Viçosa, Viçosa.2003.

SORRETINO, M. et al. Educação ambiental como política pública. Educação e Pesquisa, São Paulo, v. 31, n. 2, p. 285-299, maio/ago. 2005. 